Back pain

\section{The management of low back pain}

\section{Rossignol}

\section{Better integrated care for workers with low back pain is required}

W hen Walter Spitzer released his Quebec Task Force report on spinal disorders in 1987, the medical community was ready to receive the message that activity was better than bed rest in the management of low back pain. ${ }^{1}$ Physicians could be convinced not so much by the scientific evidence that existed at the time (the Task Force had worked on one single abstract ${ }^{2}$ ) but by their instinct and experience with other health problems such as fractures and coronary heart disease that had led the way to changing an old dogma. Bed rest was no longer to be recommended for these problems unless limited to the strict minimum. With an abundance of scientific evidence following worldwide in the 1990s to support the principle of activity in the management of low back pain, it was not too difficult to reach an international consensus of clinicians on this, ${ }^{3}$ albeit with some notable exceptions. ${ }^{4}$ But what of non-medical interest groups?

Staal et al provide us, in this issue, with a very nice description of the process by which the medical community has been able to work in consensus all along with very little help from outside. ${ }^{5}$ They use a methodology (AGREE) that highlights some of the problems that doctors have in convincing their patients who have low back pain, particularly if they are workers, that returning to their normal activities quickly is good for them. The medical consensus of returning workers to work as soon as possible directly conflicts with the sensation of pain, with the right to heal for an injured worker and with the right to work in a safe environment. The conflictual nature of this problem is at the centre of the difficulties that developed countries have in implementing the clinical guidelines on low back pain. In their analysis of the guidelines, the authors show very nicely that the apparent strength of the consensus among clinicians is easily cancelled out by their almost complete lack of face validity vis-àvis other stakeholders, particularly workers and workers' organisations. This is summarised in table 1 . The scores shown correspond to the number of guidelines, out of the six analysed in the article, that met the AGREE quality item.

The strong clinical consensus (left side of the table) and the lack of other stakeholder preoccupations (right side of the table) are also reflected in the authors summary of the language used in the guidelines regarding return to work. Recommendations are worded in terms of advice from clinicians to workers and employers, but nowhere is there an impression that advice could also be directed towards clinicians and workers' compensation agents in order to facilitate return to work.

The good news is that existing guidelines are already several years old and that novel initiatives, other than guidelines, have helped to address the basic conflict of pain and return to activity. In Quebec, 15 years after the publication of the first occupational guidelines and following 15 years of continuous arguments and discussion between the Workers' Compensation Board, clinicians, workers, and employers, we are only starting to consider sharing our differing interpretations of the scientific evidence, systematic reviews, and guidelines.

To promote the dialogue between stakeholders towards better integrated care for workers with low back pain, our research agenda should include:

(1) Getting players on side from systematic review to formulation of guidelines.
(2) Maintaining high quality systematic review protocols, with the addition of information from social sciences on anthropology and communication, and from management sciences on health and sickness management in the workplace.

(3) Developing outcome measures that will be informative about the process of returning to work in future research.

(4) Incorporating economic and policy implications for the different stakeholders in the scenarios proposed by guidelines.

The current generation of researchers on low back pain have developed methods to produce objective scientific evidence and synthesis which remain the strength of clinical discourse. The new generation will be more successful at influencing policy makers if they can also harmonise their voice with their natural partners without falling into what Pasteur warned to be the "preconceived science".

Occup Environ Med 2003;60:617

\section{Author's affiliation}

M Rossignol, Department of Epidemiology, Biostatistics and Occupational Health, McGill University, Canada

Correspondence to: $\operatorname{Dr} M$ Rossignol, Montreal Department of Public Health, 1301 Sherbrooke Street East, Montreal, Canada H2L 1M3. mrossign@santepub-mtl.qc.ca

\section{REFERENCES}

1 Spitzer WO, LeBlanc FE, Dupuis $M$, et al. Scientific approach to the assessment and management of activity-related spinal disorders. Spine 1987;12(suppl): 1-55.

2 Deyo RA, Kiehl AK, Rosenthal M. How many days of bed rest for acute low back pain? A randomized clinical trial. N Engl J Med 1986;315:1064-70

3 Koes BW, van Tulder MW, Ostelo R, et al. Clinical guidelines for the management of low back pain in primary care: an international comparison. Spine 2001;26:2504-14.

4 Deyo RA, Psaty BM, Simon G, et al. The messenger under attack, intimidation of researchers by special interest groups. N Eng J Med 1997;336: 1 176-80.

5 Staal JB, Hlobil $\mathrm{H}$, van Tulder MW, et al. Occupational health guidelines for the management of low back pain: an international comparison. Occup Environ Med 2003;60:618-26.

Table 1 Summary of which guidelines meet or do not meet the AGREE criteria

\begin{tabular}{|c|c|c|c|c|c|}
\hline & AGREE criteria strongly met & Score & & AGREE criteria poorly met & Score \\
\hline No. 6 & Target users clearly defined & $5 / 6$ & No. 20 & Cost implications considered & $0 / 6$ \\
\hline \multirow[t]{3}{*}{ No. 4} & All relevant professions included & $5 / 6$ & No. 13 & External review done & $0 / 6$ \\
\hline & & & No. 23 & Conflicts of interest recorded & $0 / 6$ \\
\hline & & & No. 22 & Independence from funding body & $0 / 6$ \\
\hline No. 16 & Clarity of management options & $6 / 6$ & No. 19 & Potential barriers discussed & $0 / 6$ \\
\hline No. 21 & Criteria for monitoring presented & $5 / 6$ & No. 10 & $\begin{array}{l}\text { Method for formulating recommendation } \\
\text { described }\end{array}$ & $1 / 6$ \\
\hline
\end{tabular}

